\title{
MODELING WAYS OF IMPROVING GREEN ECONOMY AND ENVIRONMENTAL PROTECTION IN THE CONTEXT OF GOVERNANCE
}

\author{
Iulii PYLIAVSKYI®1 ${ }^{*}$, Iryna MARTUSENKO ${ }^{\circledR 2}$, Oleksandr MOLNAR ${ }^{\circledR 3}$, \\ Halyna DZYANA (D) ${ }^{4}$, Voolodymyr KUSHNIRIUK (D) 5 \\ ${ }^{1,3}$ Department of Economic Theory, Uzhhorod National University, Uzhhorod, Ukraine \\ ${ }^{2}$ Department of Economics, Accounting and Taxation, Vinnytsia Educational and Scientific Institute of \\ Economics, West Ukrainian National University, Vinnytsia, Ukraine \\ ${ }^{4}$ Department of Public Administration of Lviv Regional Institute for Public Administration \\ of the National Academy for Public Administration, Lviv, Ukraine \\ ${ }^{5}$ Department of Public Administration, Ivano-Frankivsk National Technical University of Oil and Gas, \\ Ivano-Frankivsk, Ukraine
}

Received 10 August 2020; accepted 27 May 2021

\begin{abstract}
Today, the principles of a green economy are being updated and studied not only by experts in the field of environmental economics, but also in various political circles. A large number of countries use different instruments and principles of a green economy in their development policies and strategies. However, some countries fear this transformation because they believe that the transition to a green economy model may hinder their development. Thus, the formation of a clear methodology for the "green" economy is extremely relevant today. The main purpose of the study is to form ways to improve green economy and environmental protection in the context of governance. The article discusses the prerequisites for implementation, the basic principles of Green economy into the system of public administration, and also provides a system for modelling ways to implement the principles of Green economy using the IDEF0 methodology. This methodology allows to clearly seeing the ways and means of achieving this goal.
\end{abstract}

Keywords: Green economy, model, environment, methodology, public administration, environmental protection.

JEL Classification: Q56, Q57, G38.

\section{Introduction}

Sustainable development and Green economy requires new ideas for its implementation. Today it is obvious that for the survival and development of mankind, a transition to a new economic model of development is needed. Such a model is recognized as a model of the economy of "Green economy". Sustainable development remains the most important longterm goal, but to achieve it, the economy needs to be made green. The sustainable development model provides for a comprehensive relationship between the three components of development: economic, social and environmental. The concept of environmental economic growth is designed to provide a more harmonization of these three components, which would be acceptable to all countries of the world, regardless of level of development.

Without the introduction of fundamentally new approaches to the formation of social development strategies, it is impossible to offer a way out of the current situation of a complex crisis at the global level of a dangerous combination of fuel and food, financial and climate crises. Collectively, global crises deepen pressing socio-economic problems related to job cuts, social insecurity and poverty. Preserving the "polluting" economy with its traditional dependence on non-renewable energy sources, wasteful use of material resources, high climate risks and investing in unstable sectors of the economy will reproduce the same imbalances and will make permanent those global crises that humanity is facing today. The transition to the principles of "Green economy" and a reduction in investment in fossil fuels and other "polluting" sectors while increasing investments in renewable energy, energy conservation, public transport, sustainable agriculture, the protection and rational use of land and water resources will allow provide a solution to these problems.

*Corresponding author. E-mail: oli2727@yahoo.com 
The concept of Green economy is based on the assumption that economic and environmental policies can stimulate Green economy and increase carbon and energy and material efficiency while preserving natural assets and improving people's quality of life (Deschenes, 2010).

The concept of environmental growth is gaining increasing public resonance. It is actively discussed by scientists, experts, politicians, non-governmental organizations. The term "Green economy" was first used by a group of scientists from the London Center for Environmental Economics (LEEC). Although it should be recognized that various aspects of the environmental problem and the possibilities of its solution were raised by scientists much earlier (Arrow et al., 2012).

A Green economy theory does not favor any one political theory. It is possible in any economy, state or market, is not an alternative to sustainable development. Rather, it is a way of pursuing a course towards such development at the national, regional and world levels and in ways.

The main hypothesis of the study is to find and systematize the main ways to improve the green economy and environmental protection in the context of government activities. This goal was realized using a functional model IDEF0 that allows to depict complex and multi-stage processes in the most understandable way.

\section{Theoretical framework}

\subsection{Literature review}

Issues of the development of green economy principles in the context of governance have begun to be studied relatively recently. The initial impetus to these studies was the global awareness of the importance of implementing the principles of greening at all levels of the state administration apparatus.

The highest goal of global civilization, according to Khutorova (2019), is today the creation of an extra-national citizen of a single world state, which will be characterized by special mobility to harsh changes in living conditions, professions, and cultural environment. To this, in light of the existing environmental contradictions, it is justifiable to add a responsible attitude to the environment as a key attribute of the modern citizen of the world against the backdrop of the crisis in the environmental component of economic development.

Substantiation of the expediency of building a "green economy" was offered more than a quarter of a century ago. However, the need to switch to "green rails" has become especially relevant today (Pichert \& Katsikopoulos, 2008).

The historical aspects of applying the principles of a green economy, as well as their implementation in their study, were presented by authors such as Volkery and Rouabhi (2015).

Lutsko (2019), in his work, systematized the basic aspects of the concept of a green economy, came to the conclusion that it:
- improves the standard of living of the population;

- makes it possible to efficiently and rationally use existing energy resources;

- minimizes harmful emissions while protecting the environment;

- reduces costs of ecosystem development and supports biodiversity.

After more than one scientist formed the basic principles and characteristics of green economy, the next step was to find ways of its development and renationalization in practice. One of these scientists was Low (2011), who in his work presented the principles of the practical development of green economy. In subsequent years, Satbyul et al. (2014) worked in this scientific field, who explored new principles for determining the level of green economy using the example of South Korea.

In recent years, these studies were continued by Pidlisnyuk et al. (2020), who in their work developed strategic principles for Green economy in the context of modern climate change

In particular, Zervas (2012) and Ahlert and Meyer (2013) in their works investigated the influence of the latest developments in the field of Green economy, in particular in the field of energy, environmental protection, in the context of landscape objects. In his work, the principles of greening the economic development of states, both at the level of an individual enterprise and at the level of the whole state, were developed.

Another scientist who studied the concept of green economy can be considered Berezhnaya (2019), who in her work systematized the international aspects of green economy, studying the experience of leading countries of the world. This work covered both research at the industry level and at the level of government.

While Vanieva (2020) explored the financial and economic instruments of green economy, which are recognized as another way to create an environmentally friendly system of government and production that offers less polluting products and services, as well as changing consumer behavior.

Bowen (2012) investigated issues of optimizing the labor market and methods for finding new jobs in the context of implementing green economy principles.

Chmyr and Zakharkevich (2020) in his work presented the foundations of green economy in public administration. The basis of his work was the efficient use of natural resources, as well as the optimization and preservation of landscape objects.

Considering the above studies, we can come to the conclusion that today there are a significant number of principles and mechanisms aimed at the gradual improvement of the green economy, both at the general economic and international levels of governance. Mostly all these principles are not systematized and look like a stochastic set of optional rules and norms. Thus, an important element of this study is the creation of a clear and systematized model that will allow us to understand the algorithm for performing actions when achieving the set goals. 


\subsection{Theoretical prerequisites for methodology development}

The success of the implementation of government initiatives aimed at sustainable economic growth, to a large extent, depends on a stable understanding in the minds of people of the norm of attitude to the natural environment and social responsibility. However, even the position of "environmental indifference" has been formed over decades, can be transformed in response to transparent and effective steps by authorities in the direction of implementing the concept of sustainable development and green economy at the national level, which are accompanied by a comprehensive popularization of environmentally friendly behavior and the idea that environmental degradation is part of economic development - the problem of every citizen, since its consequences will have a negative impact on the welfare of all excluding the inhabitants of the Earth (Kuhnhenn, 2018).

In the context of intensive globalization, integration and transnationalization of the economy, a number of problems, among which an important place belongs to the formation of an "environmentally oriented" mentality, are gaining global scale, are being updated internationally and are losing nationality. Accordingly, the goals of human development are also being transformed (Denona \& Sverko Grdic, 2020).

The concept of green economy includes the ideas of many areas of economic science and philosophy and ecology, such as environmental economics, feminist economics, postmodernism, resource-oriented economics, environmental economics, anti-consumerism, antiglobalism, green anarchism, green politics, the theory of international relations, etc. related to sustainable development and green economy problems.

The green economy and Sustainable Development Strategy identifies a number of key trends requiring action, as well as a number of long-term goals and specific measures at EU level to achieve those (Breitschopf et al., 2011):

- limiting climate change. The first long-term specific objective of the strategy is to limit climate change and its consequences by fulfilling the obligations of the Kyoto Protocol and the European Strategy for Climate Change. The subject of special labor is energy efficiency, renewable energy and transport;

- limiting the negative effects of transport and reducing regional differences is another long-term goal. It has been determined that it is necessary to make transport environmentally friendly and healthy. The strategy includes, inter alia, charging for infrastructure, promoting alternatives to road transport and vehicles that produce less pollution and consume less energy;

- the promotion of more sustainable modes of production and consumption. It is recognized that it is necessary to break the link between economic growth and environmental degradation and pay attention to what kind of load ecosystems can withstand. To this end, the EU should, among other things, promote green public procurement, set environmental and social performance targets for products in collaboration with stakeholders, disseminate environmental innovations and environmental technologies, and provide information and appropriate labeling of products and services;

- sustainable management of natural resources. The strategy envisages avoiding over-exploitation of natural resources, increasing the efficiency of their use through recycling, and recognizing the value of ecosystem services. In particular, the EU must make efforts in the field of agriculture, fisheries and forest management so that the Natura-2000 network is completed; identify and implement priority actions for the protection of biodiversity and ensure that due consideration is given to aspects related to the seas and oceans;

Green economy theory is based on three axioms (O’Neill, 2018):

- it is impossible to infinitely expand the sphere of influence in a limited space;

- it is impossible to demand the satisfaction of infinitely growing needs in conditions of limited resources;

- everything on the surface of the earth is interconnected.

Green sectors of the economy provide for a change in the structure of the economy in which (Grubler, 2018):

- more attention is paid to the social aspect of sustainable development (social cohesion, ensuring access to a variety of resources, combating poverty and unemployment, etc.),

- the economy is based not only on the extractive sector, but more and more on the processing sector and the service sector;

- dominated by investments in environmentally friendly production, consumption, as well as improving the quality of goods and services from an environmental point of view;

- natural resources are used on an ongoing basis, not dependent on fossil fuels;

- forms new economic opportunities, expanding the scope of economic development and reducing poverty;

- an "ecological working system" is taking shape in agriculture, industry, in research and development, in administrative activities and in the service sector.

Today, the theory of a green economy is considered a new type of strategy based on environmentally friendly, resource-saving and optimizing principles of landscape technologies and using innovative methods and technologies to implement the principles of green development. This system adapts the modern principles of production and the way of life of the state. The concept of a green economy should be understood as a low-carbon, resourcesaving theory that aims to implement the principles of 
landscape optimization and the formation of a socially inclusive model of the economy, which is being developed as a more practical version of the concept of sustainable development (Prakash \& Potoski, 2006).

Since 1992, great efforts have been made by the world community to achieve sustainable development of Green economy at the local, state and international levels. At the UN Millennium Forum (2000), countries agreed on a number of the Millennium Development Goals (MDGs).

\section{Methodology}

For the specification and visual modeling of ways to improve green economy in the context of government in the field of ensuring green economy and environmental safety, we have chosen a functional modeling methodology and a graphical description of the processes (IDEF0). The reason for choosing this model among others was that during its construction, the emphasis is on the phasing and characteristics of subcontracting elements of the model. In our opinion, this type of modeling itself will allow us to fully depict the sequence and conceptualism of ways to improve green economy in the context of government.

In its general theoretical form, the IDEF0 functional model is intended to describe existing processes that use both natural and graphic languages. To transmit information about a particular system, the source of the graphic language is the IDEF0 methodology itself.

The IDEF0 methodology allows you to form a hierarchical system of diagrams in the form of single descriptions of system fragments. The first stage is a detailed description of the system and its interaction with the outside world, after which functional decomposition is implemented by fragmentation into separate subsystems. Each subsystem is described separately in the form of decomposition diagrams. After that, these subsystems are fragmented into even smaller blocks until the final goal is achieved.

The blocks in IDEF0 are arranged in a hierarchical order, as the author of the diagram understands. This order is built on the principle of domination. Dominance can be understood as the purposeful impact of one block on other blocks of the diagram.
The idea of IDEF0 is that processes (functions of a real object) are represented as some transformations of an input stream into an output stream under the control (control) of a control stream with implementation for the transformation of the mechanism.

The main advantages of IDEF0 are as follows:

- completeness of the description of the process (control, information and material flows, feedback);

- complexity in decomposition (migrations and tunneling arrows);

- the ability to aggregate and drill down streams of data and information (splitting and merging arrows);

- the presence of strict requirements of the methodology, ensuring the receipt of process models of a standard form.

To begin with, for the basic formation of the goal of our research, we need to create a functional diagram of the highest level A-0, which will be the main in the process of constructing a functional model IDEF0. Given this, in Figure 1, which was created with special software by the authors, we systematized the most significant elements of modeling ways to improve the process of Green economy and environmental safety in the country.

The scheme developed by us allows us to see a list of the main ways to improve the principles of green economy in the country. This hierarchical structure is a simplified model. The next step will be the use of functional mechanisms IDEF0, which will allow expanding and detailing the paths to fully understand the whole algorithm of the process of improving green economy in the country.

\section{Results and discussions}

In order to fully realize the functional properties of the IDEF0 model, at this stage it is necessary to use its main feature, namely, that in this model each block implements the process of transforming inputs into outputs, while attracting certain volumes and types of resources. Given this, having formed and depicting the main goal in the form of $\mathrm{A} 0$, the next step in our modelling should be the formation and schematization of the initial elements that are necessary to achieve the goal in the form of a context diagram (Figure 2). The context diagram is one block

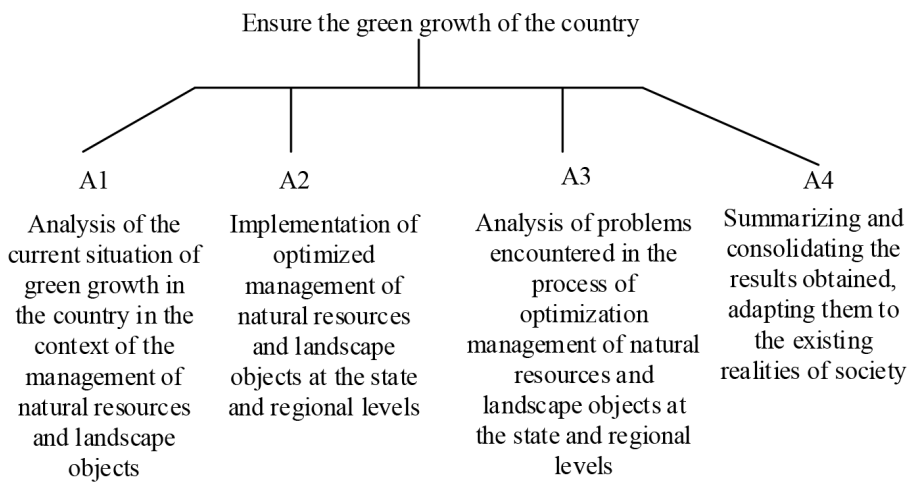

Figure 1. Hierarchical structure of functional model IDEF0 of the main ways to improve the principles of green economy in the country (developed by authors) 


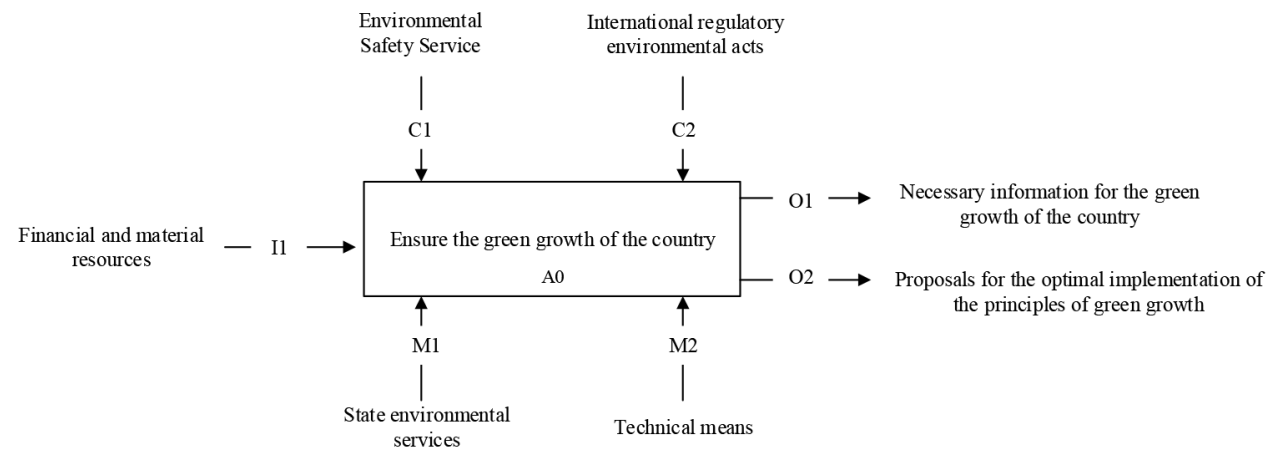

Figure 2. Context diagram of elements of model IDEF0 of the main ways to improve the principles of green economy in the country (developed by authors)

with arrows that reflect the relationship of the described process with the external environment. Thus, we can say that the context diagram shows the modeling region and its boundaries. The name of the block corresponds to the name of the described function (process).

For a better understanding of the functional and systematic features of the model we constructed, it would be advisable to explain its basic elements.

The input element, which is indicated by the symbol "I", in our case, means the financial and material resources necessary to achieve the goal. This group includes those resources that are already available for use, as well as those that need to be obtained in the future.

Control objects were marked as the symbol " $\mathrm{C}$ ":

- C1 - environmental safety service. With the help of this set, it becomes possible to form internal regulatory information, which is important for the realization of the final goal.

- C2 - international rules, this is a division of use for obtaining regulatory information coming to the state from the outside and forms an innovative and corrective basis for achieving the final goal.

The objects of the mechanism were designated by us with the symbol "M":

- M1 - state environmental services. These objects take a more prominent place in the process of implementing the principles of green economy in the country. They determine the order, as well as the features of this process.

- M2 - technical means. Specific technical tools that are formed to implement the principles of green economy in the state are the basic mechanisms for achieving the goal, given that they are the reflection of its practical implementation.

The last elements of this model are outputs that demonstrate the result that we can get at the outputs of the practical implementation of the IDEF0 functional model. These elements are marked with an "O" symbol:

- O1 - this information is generated after all elements of the model are completed and it becomes possible to generate an assessment of the results.

- O2 - Proposals for the optimal implementation of the principles of green economy. These proposals can be formed only after a full passage of all stages, as well as after a secondary analysis and adjustment of their shortcomings and features.

After we have presented and described all the functional elements of the IDEF0 model, the next step will be the reflection of their functional interactions and interconversions. To do this, we built decompositions of the first level of the process of improving Green economy processes in the state (Figure 3).

It is worth noting that this decomposition of the first level can be considered the initial stage. This is due to the fact that if for a better understanding of the technology and mechanisms, as well as to explain the practical implementation of this goal, it is necessary to detail the above steps, this model will allow us to build decompositions of the second, third and further levels.

Given the above decomposition, it will be useful to explain the content of each stage of the process of improving Green economy in the state, in particular in public administration.

Given the decomposition presented, it would be advisable to explain the content of each of the stages of the process of improving green economy in the country, in particular in government:

- A1 - analysis of the current situation of green economy in the country in the context of the management of natural resources and landscape objects. This stage provides for the implementation of a thorough analysis of the existing situation with the subsequent identification of the most problematic areas, as well as the main prospects for the processes and mechanisms of managing natural resources and landscape objects.

- A2 - the introduction of optimized management of natural resources and landscape objects at the state and regional levels. At this stage, an attempt is made to reconcile primary measures to improve the process of green economy in the context of optimizing the public administration process. It is worth noting that this stage cannot be considered final, since after it a full assessment of the effectiveness of the measures taken should take place.

- A3 - analysis of problems arising in the process of optimizing the management of natural resources and landscape objects at the state and regional levels. During this stage, the analysis and assessment 


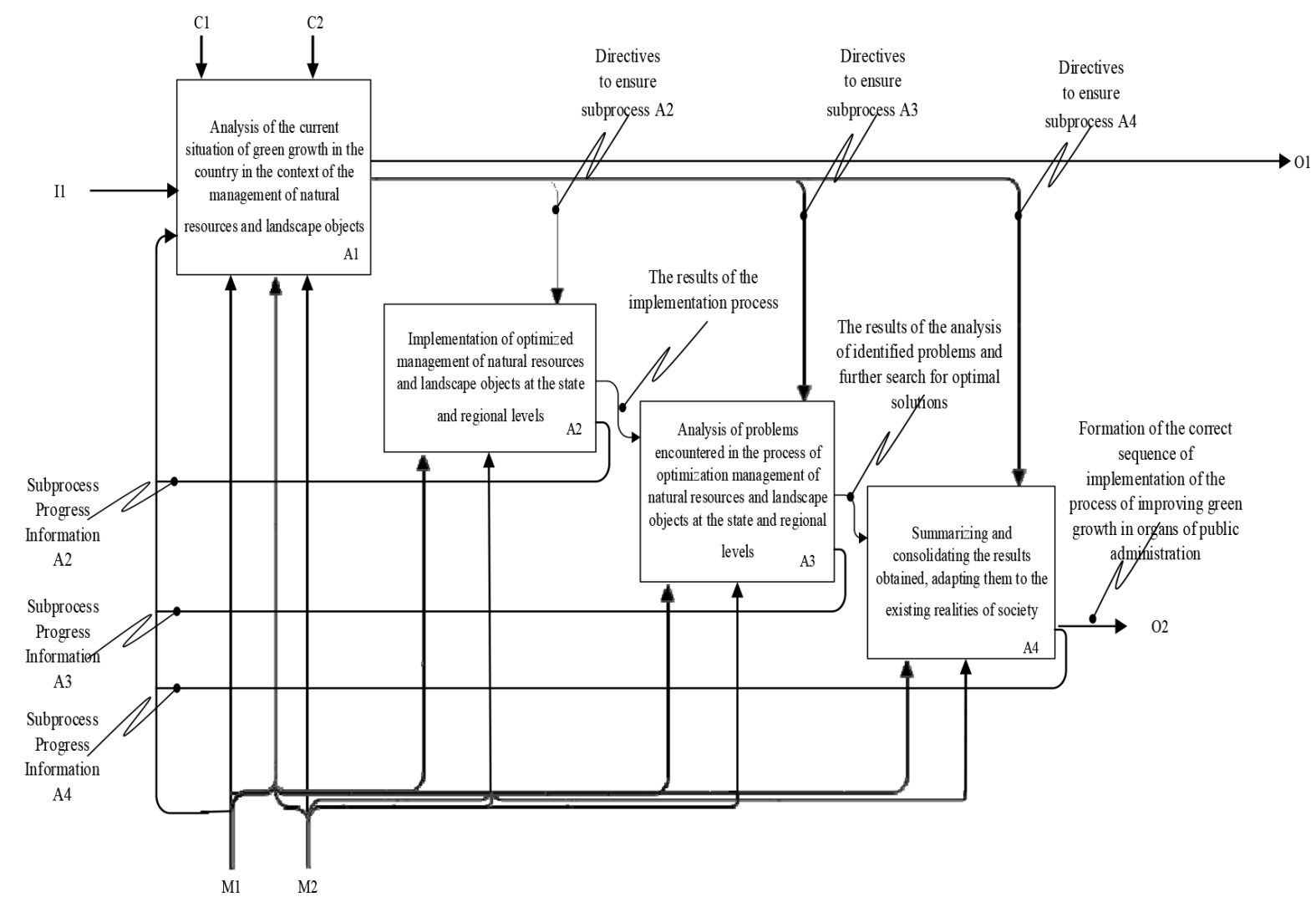

Figure 3. Decompositions of the first level of functional model IDEF0 of increasing the creativity of psychology students (developed by authors)

of those problems or difficulties that arose in the second stage in the process of optimizing the management of natural resources and landscape objects at the state and regional levels. In the following, based on the analysis of these problems, it will be possible to formulate and implement the necessary adjustments.

- A4 - generalization and consolidation of the results obtained their adaptation to the existing realities of society. During this stage, the results are systematized and a holistic paradigm of the process of improving green economy in the country is formed in the context of optimizing the resource base and landscape objects. This paradigm should be characterized by flexibility and adaptability, as it should be simply implemented for different countries.

Each of these stages is a generalization of branched and complex processes. In the decomposition of the following levels, this model makes it possible to fully specify them under existing realities.

The last elements that are not described by us are intermediate inputs, outputs, control mechanisms, which are depicted in the form of arrows on the constructed functional model IDEF0. These elements consist of the following parts:

- subprocess management directives A2, A3, A4 - represent the results of the praise of the entities that con- trol the process of monitoring the implementation of these steps;

- the output "Information on the progress of the subprocess A2, A3, A4" - represents the information that the entities responsible for the process of monitoring the implementation of these stages receive from each subprocess. Based on this information, decisions are made on the completion of subprocesses and the transition to the following.

The next steps of our study became the practical implementation of this model. It was applied in separate structural units of government in Eastern Europe, in particular in Poland and Ukraine. After applying this model, we carried out an analysis that showed the dynamics of the effectiveness of managerial decision-making in the field of improving Green economy processes. As a result, after conducting this analysis, we can say that the efficiency of the activities of these structural units has objectively improved, since the number of successfully implemented management decisions in the field of improving Green economy has increased. These indicators are shown in Figure 4, which clearly demonstrate the effectiveness of our model.

Given the above indicators, we can conclude that the model we have formed is effective. In the future, this model can be transformed and specified for the existing realities and features of the functioning of public administration in each country. 


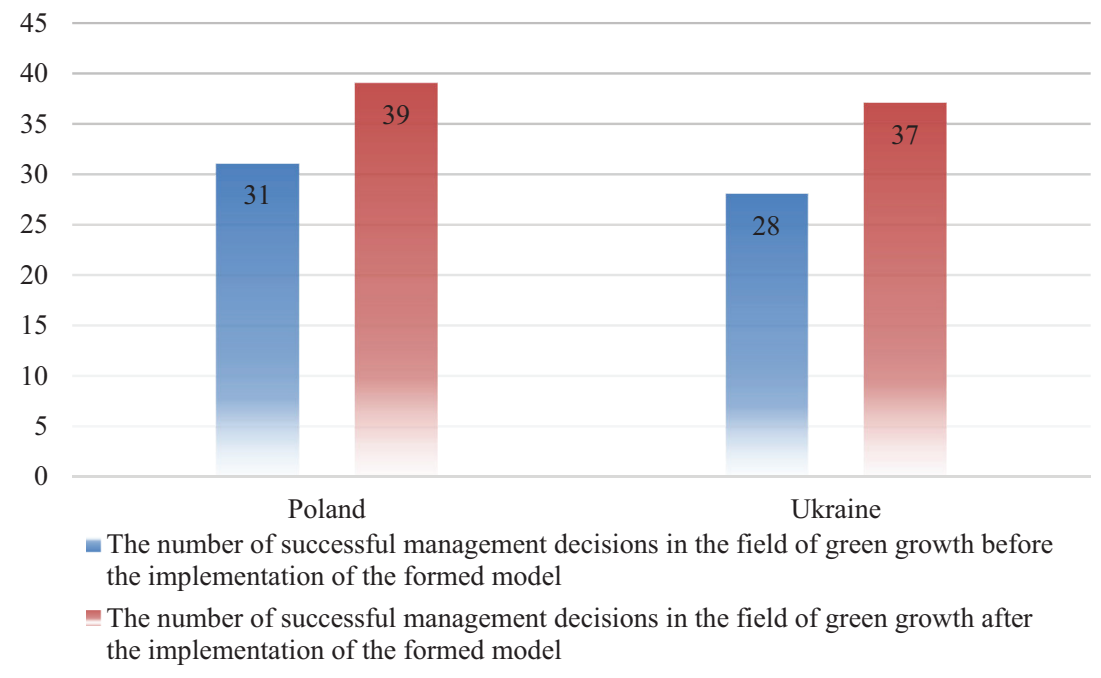

Figure 4. Dynamics of successfully implemented management decisions in the field of green economy after the implementation of our model in Poland and Ukraine (developed by authors)

\section{Conclusions}

Green economy means fostering economic growth and development in which natural assets continue to provide resources and environmental services. Green economy provides a practical and flexible approach to achieve concrete, measurable progress on all its economic and environmental principles, while at the same time fully taking into account the social consequences of greening the dynamics of economic growth. The focus of Green economy strategies is to ensure that natural assets can fully realize their economic potential in a sustainable manner. This potential includes the provision of critical life support services - clean air and water, as well as sustainable biodiversity, necessary to maintain food production and human health. Natural assets are not infinitely replaceable, so Green economy policies take this into account.

Within the framework of our research, the methodology of functional modeling and graphical description of processes (IDEF0) was used. This functional model is given the opportunity to visually show the process of improving the green economy within the country, in particular at the government level. After the theoretical formation of all stages of this model, it was applied within the framework of the structural units of management in Ukraine and Poland. After its implementation and analysis, it can be concluded that this model is effective and can be used in the context of improving the performance of the green economy in government.

The use of this methodology will allow preserving the ecosystem, biodiversity of the country, minimizing and rationalizing the consumption of energy, water and other types of resources. Through the introduction of highly efficient green technologies, it is possible to achieve a reduction in carbon emissions and to minimize or even prevent the generation of all forms of waste and pollution. The scheme we have developed allows you to see a list of the main ways to improve the principles of a green economy in the country. This hierarchical structure is a simplified model. The next step will be to use the functional mechanisms of IDEF0, which will expand and detail the ways for a complete understanding of the whole algorithm of the process of improving the green economy in the country.

\section{Author contributions}

The authors contributed equally.

\section{Disclosure statement}

The authors do not have any conflict of interest.

\section{References}

Ahlert, G., \& Meyer, B. (2013). Synopsis of approaches to Welfare and of Green economy concepts currently under discussion. GWS - Institute of Economic Structures Research, Osnabrück.

Arrow, K., Dasgupta, P., Goulder, L. H., Mumford, K., \& Oleson, K. (2012). Sustainability and the measurement of wealth. Environment and Development Economics, 17(3), 317-353. https://doi.org/10.1017/S1355770X12000137

Berezhnaya, Yu. (2019). The concept of "Green economy": international aspect. In Jurisprudence. Scientific notes Tauride National University named after Vernadsky No. 1 (pp. 210-215). TNU Publisher.

Bowen, A. (2012). "Green" growth, "green" jobs and labor markets. Working Paper, Grantham Research Institute, London, UK. https://doi.org/10.1596/1813-9450-5990

Breitschopf, B., Nathani, C., \& Resch, G. (2011). Methodological guidelines for estimating the employment impacts of using renewable energies for electricity generation. "Economic and Industrial Development" EID - EMPLOY. In Final report Task 1 . Study commissioned by IEA-RETD (Renewable Energy Technology Deployment).

Chmyr, A., \& Zakharkevich, N. (2020). Green economy: essence, goals and basic principles. Economic Bulletin of Donbass, 2013.3 (33), 54-62. 
Denona, N., \& Sverko Grdic, Z. (2020). Transitioning to a Green economy - possible effects on the Croatian economy. Sustainability, 12(22), 1-19.

https://doi.org/10.3390/su12229342

Deschenes, O. (2010). Climate policy and labor markets. In NBER Working Papers, No. 16111. National Bureau of Economic Research, Cambridge, Massachusetts. https://doi.org/10.3386/w16111

Grubler, A. (2018). A low energy demand scenario for meeting the $1.5 \mathrm{C}$ target and sustainable development goals without negative emissions technologies. Nature Energy, 3, 515-527. https://doi.org/10.1038/s41560-018-0172-6

Khutorova, N. (2019). Ecological modernization - from theory to practice. Forest Herald Journal, 1, 33-40.

Kuhnhenn, K. (2018). Economic growth in mitigation scenarios: a blind spot in climate science (pp. 209-212). Heinrich Boll Foundation.

Low, L. (2011). Green economy: implications for development planning. Climate and Development Knowledge Network.

Lutsko, V. (2019). Power, technologically ecological security and human rights. In National Conference "50 anniversary of the general declaration of human rights" (pp. 161-165). Kyiv, Ukraine.

O’Neill, D. (2018). A good life for all within planetary boundaries. Nature Sustainability, 1(2), 88-95. https://doi.org/10.1038/s41893-018-0021-4

Pichert, D., \& Katsikopoulos, K. (2008). Green defaults: information presentation and pro environmental behaviour. Journal of Economic Psychology, 28(1), 63-73. https://doi.org/10.1016/j.jenvp.2007.09.004
Pidlisnyuk, V., Zagirnyak, M., \& Irkova, I. (2020). Strategy for Green economy and climate change. Kremenchug Publishing house "Scherbatykh".

Prakash, A., \& Potoski, V. (2006). The Voluntary Environmentalists: Green Clubs, ISO 14001, and Voluntary Environmental Regulations. Cambridge University Press. https://doi.org/10.1017/CBO9780511617683

Satbyul, K., Ho, K., \& Yeora, C. (2014). A new approach to measuring green economy: application to the OECD and Korea. Futures, 63, 37-48. https://doi.org/10.1016/j.futures.2014.08.002

Vanieva, A. (2020). Creation and search for promising natural resources based on secondary resources. http://www.rusnauka. com/14_ENXXI_2013/Economics/13_136553.doc.htm

Volkery, A., \& Rouabhi, S. (2015). Green economy and sustainable development. A historical account of the discourse around sustainable development and Green Economy. In KNOSSOS Policy Briefings: Green Economy, Discussion Paper. UNEP, IEEP, GLOBE-EU. http://www.unep.org/research4policy/policybriefs/tabid/78428/Default.aspx

Zervas, E. (2012, December 2-4). Green economy versus Sustainable Development. Recent advances in energy, environment and economic development. In S. Eslamian (Ed.), Proceedings of the 3rd International Conference on Development, Energy, Environment, Economics (DEEE '12) (pp. 399-404). Paris, France. 